\title{
Expression and significance of GRHL2 in esophageal cancer
}

This article was published in the following Dove Press journal:

OncoTargets and Therapy

7 April 2017

Number of times this article has been viewed

\author{
Chengcheng Shao' \\ Chushu Ji' \\ Xiaoqiu Wang ${ }^{2}$ \\ Bing $\mathrm{Hu}^{\prime}$ \\ 'Department of Medical Oncology, \\ 2Department of Pathology, \\ Anhui Provincial Hospital, \\ Anhui Medical University, Hefei, \\ People's Republic of China
}

\begin{abstract}
Esophageal cancer (EC) is one of the most common causes of cancer-related mortality in the world. Although much effort has been made to improve the 5-year survival rate of patients with EC, it still remains low due to diagnosis at an advanced stage, aggressive local invasion, early metastasis, and resistance to chemotherapy. Although grainyhead-like 2 (GRHL2) has attracted interest since it has been recently identified as a novel suppressor of the epithelialmesenchymal transition, clinical values of GRHL2 and its relationship with the metastasis-related factors, such as hypoxia-inducible factor $1 \alpha(\mathrm{HIF}-1 \alpha)$ and vascular endothelial growth factor (VEGF), remain unclear. In order to investigate the expression of GRHL2, HIF-1 $\alpha$, and VEGF, and their correlation with angiogenesis in EC, 63 patients with EC were examined. The expression of GRHL2, HIF-1 $\alpha$, and VEGF in tumor tissues was higher than that in adjacent tissues and was associated with tumor differentiation. GRHL2 expression was significantly correlated with lymph node metastasis and invasion depth, whereas VEGF expression was associated with tumor (TNM) stage. A significant correlation was found between the expression of GRHL2 and HIF-1 $\alpha$. The patients expressing low GRHL2 and high HIF- $1 \alpha$ showed significant reduction in both overall survival rate and disease-free survival rate. The results demonstrated that abnormal expression of GRHL2 is common in EC, and low expression of GRHL2 accompanied by a high expression of HIF- $1 \alpha$ indicates poor prognosis.
\end{abstract}

Keywords: esophageal neoplasms, GRHL2, HIF-1 $\alpha$, VEGF, MVD

\section{Introduction}

Esophageal cancer (EC) is the sixth most common cause of cancer-related mortality in the world, with an estimated 455,000 new cases and 400,000 deaths worldwide in 2012. ${ }^{1}$ About half of the EC cases that are newly diagnosed each year worldwide occur in eastern Asia, especially in Linxan, People's Republic of China. ${ }^{1}$ Although the 5-year relative survival rate of patients with EC has improved during the past 3 decades, it still remains low at about $20 \%$ due to diagnosis at an advanced stage, aggressive local invasion, early metastasis, and resistance to chemotherapy and adjuvant therapy. ${ }^{2,3}$ The prognosis and choice of therapy for patients with EC are determined by the cancer stage. ${ }^{4}$ However, there is an increasing evidence that even patients with the same pathologic stage of EC may have considerable differences in outcome after complete surgical resection, and so it is not sufficient to precisely predict individual prognosis on the basis of the current staging system alone. Therefore, there is an urgent need to discover more biomarkers and therapeutic targets for EC.

Advances in molecular biology have led to the discovery of a variety of new molecules that contribute to carcinogenesis and tumor progression. Grainyheadlike 2 (GRHL2), a mammalian homolog of Drosophila grainyhead, is a member of grainyhead-like (GRHL) transcription factor family. GRHL is a newly discovered
Correspondence: Bing Hu Department of Medical Oncology, Anhui Provincial Hospital, Anhui Medical University, No 17 Lujiang Road, Hefei 23000I, Anhui, People's Republic of China Tel/fax +86 55I 62283337 Email hubing20I3oncol@gmail.com

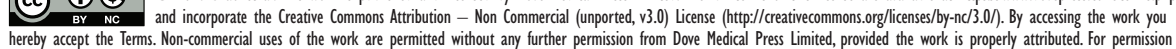
for commercial use of this work, please see paragraphs 4.2 and 5 of our Terms (https://www.dovepress.com/terms.php). 
family of tissue- and development-specific genes including three distinct members: GRHL1, GRHL2, and GRHL $3 .{ }^{5}$ It has been shown that GRHL1 regulates epidermal differentiation, as the Grhl1-/- mice has been found to exhibit palmoplantar keratoderma, impaired hair anchoring, and desmosomal abnormalities, ${ }^{6}$ whereas GRHL3 acts as a direct activator of PTEN expression, and deletion of GRHL3 in adult epidermis has been shown to result in aggressive squamous cell carcinoma induced by evoking of PI3K/AKT/mTOR signaling. ${ }^{7}$ Recently, GRHL2 has drawn much attention for its function in regulating developmental neural tube closure, and modulating the epithelial-mesenchymal transition (EMT), partly due to the activation of target genes including claudin-4 and E-cadherin. ${ }^{8}$ To date, a few studies have focused on the role of GRHL2 protein in the development of cancer. However, its clinicopathological significance as an independent prognostic factor of EC has not yet been investigated.

EMT is a pathological process by which epithelial cells lose their cell polarity and cell-cell junction, and acquire a mesenchymal phenotype. EMT results in enhanced mobility and invasiveness of carcinoma cells, which is considered as a crucial early step in cancer progression and metastasis. ${ }^{9-11}$ Together with the progression of tumor, angiogenesis provides necessary nutrients and oxygen for tumor cells, and also plays a key role in facilitating proliferation and metastasis. ${ }^{12}$

Vascular endothelial growth factor (VEGF), an endothelial cell-specific mitogen, mediates related proteins contributing to key steps in tumor angiogenesis and vascular permeability. ${ }^{13}$ The upstream gene of VEGF, hypoxiainducible factor $1 \alpha$ (HIF-1 $\alpha)$, is overexpressed in the early stages of carcinogenesis, and is correlated with diagnostic and prognostic indicators; this makes HIF-1 $\alpha$ a potential therapeutic target. ${ }^{14}$ Under hypoxic stress, HIF-1 $\alpha$ binds with HIF-1 $\beta$, and controls the expression of downstream target genes, including genes that participate in EMT. ${ }^{15}$ Recently, the GRHL2 protein has received more attention as a potent prognosis factor with regard to its roles in tumor EMT. ${ }^{16-18}$ To the best of knowledge, expression of the GRHL2 protein in connection with tumor angiogenesis in human EC has not yet been elucidated.

The present study investigated the expression of GRHL2, HIF-1 $\alpha$, and VEGF protein by immunohistochemistry in specimens surgically resected from 63 patients with EC, and analyzed the relationships of these proteins with various clinicopathological features and prognosis of patients. Furthermore, this study also investigated the possible angiogenic role by comparing the expression of these three proteins with intratumoral microvessel density (MVD) and assessed the independent prognostic factors affecting longterm survival.

\section{Materials and methods Patients}

Esophageal carcinoma and the paired adjacent normal tissues were obtained from patients who were diagnosed with EC and had undergone a subtotal esophagectomy from April 2009 to May 2011, at the Department of Thoracic Surgery, Anhui Provincial Hospital. None of these patients had received radiotherapy or chemotherapy before surgery and had no distant metastases. Data on the clinicopathological features of the disease and follow-up of the patients were collected from their medical records and pathological reports. Written informed consent was obtained from all the patients, and the study protocols were approved by the Ethics Committee of Anhui Provincial Hospital.

\section{Immunohistochemical (IHC) analysis and evaluation}

IHC staining was performed on $4-\mu \mathrm{m}$ sections obtained from formalin-fixed paraffin-embedded blocks. Sections were deparaffinized in xylene, and rehydrated in gradient alcohol. Endogenous peroxidase activity was blocked using 3\% hydrogen peroxidase. Antigen was retrieved by pressure cooking for 3 minutes with Tris/ethylenediamine tetraacetic acid ( $\mathrm{pH} 8.0)$. Then, the slides were incubated with diluted antibodies (GRHL2, 1:100, ab86611 [Abcam, Cambridge, UK]; HIF-1 $\alpha, 1: 100$, ab113642 [Abcam]; VEGF, 1:100, 19003-1-AP [Proteintech, Rosemont, IL, USA]; antiCD34, 1:100, 60180-1-Ig [Proteintech]) overnight at $4{ }^{\circ} \mathrm{C}$. After incubation with the secondary antibody for 30 minutes, the sections were stained with 3,3'-diaminobenzidine. Finally, the sections were counterstained with hematoxylin, dehydrated, and mounted.

Brown granules of HIF-1 $\alpha$, VEGF, and GRHL2 indicated positive expression. The staining intensity was scored as follows: 0 , no staining; 1 , mild staining; 2 , moderate staining; and 3, intense staining. The area of staining was scored as follows: $0,<10 \%$ of tissues stained positive; 1 , between $10 \%$ and $25 \%$ of tissues stained positive; 2 , between $25 \%$ and $50 \%$ of tissues stained positive; and 3, $>50 \%$ of tissues stained positive. IHC score was calculated as the product of the staining intensity and staining extent, where $0-1$ indicated a negative score (-), 2-3 a weak positive score $(+)$, and 4 a positive score $(++)$. 


\section{Evaluation of tumor MVD}

The IHC staining of CD34 was used for MVD counting. First, sections stained for CD34 were scanned at a low magnification $(\times 100)$, and areas with a high density of highlighted microvessels were identified. Then, five hot spots were selected randomly and observed, and the values of MVD were counted by scanning at a magnification of $\times 200$. The mean score of the five areas was then calculated as the value of MVD for each section.

\section{Statistical analysis}

Values are presented as mean \pm standard deviation. Statistical analysis was performed using SPSS 17.0 (SPSS, Inc., Chicago, IL, USA). The statistical significance of differences between groups was evaluated by two-tailed Pearson's $\chi^{2}$ test. Survival curves were plotted using the Kaplan-Meier method. Statistical significance was defined as $P<0.05$.

\section{Results}

\section{Expression of GRHL2, HIF-I $\alpha$, and VEGF in EC tissues and adjacent normal tissues}

The cell membrane and cytoplasm were stained brown in cells positive for GRHL2, HIF-1 $\alpha$, or VEGF (Figure 1). The expression levels of GRHL2, HIF-1 $\alpha$, and VEGF in EC tissues were remarkably higher than those in the corresponding adjacent normal tissues (Table 1), which indicated that all these proteins may be involved in the progression of EC.

\section{Correlation of GRHL2, HIF-I $\alpha$, and VEGF expression in EC tissues}

In order to investigate the relationship between the expression of GRHL2, HIF-1 $\alpha$, and VEGF and clinicopathological parameters in the 63 patients with EC, they were divided into groups as follows: low GRHL2 and high GRHL2 groups, low HIF- $1 \alpha$ and high HIF- $1 \alpha$ groups, and low VEGF and high VEGF groups. Significant correlations were found between the expression of all these three proteins and tumor differentiation. GRHL2 expression was significantly correlated with lymph node metastasis and invasion depth, whereas VEGF expression was associated with tumor (TNM) stage. Furthermore, higher expression of VEGF also indicated more advanced tumor stage and higher MVD. There were no statistical connections between the expression of these three proteins and the clinicopathological parameters (Table 2 and Figure 2).

\section{Low expression of GRHL2 and high expression of HIF-I $\alpha$ indicate poor prognosis}

As the expression of GRHL2, HIF-1 $\alpha$, and VEGF was higher in EC tumor tissues than the adjacent normal tissues and

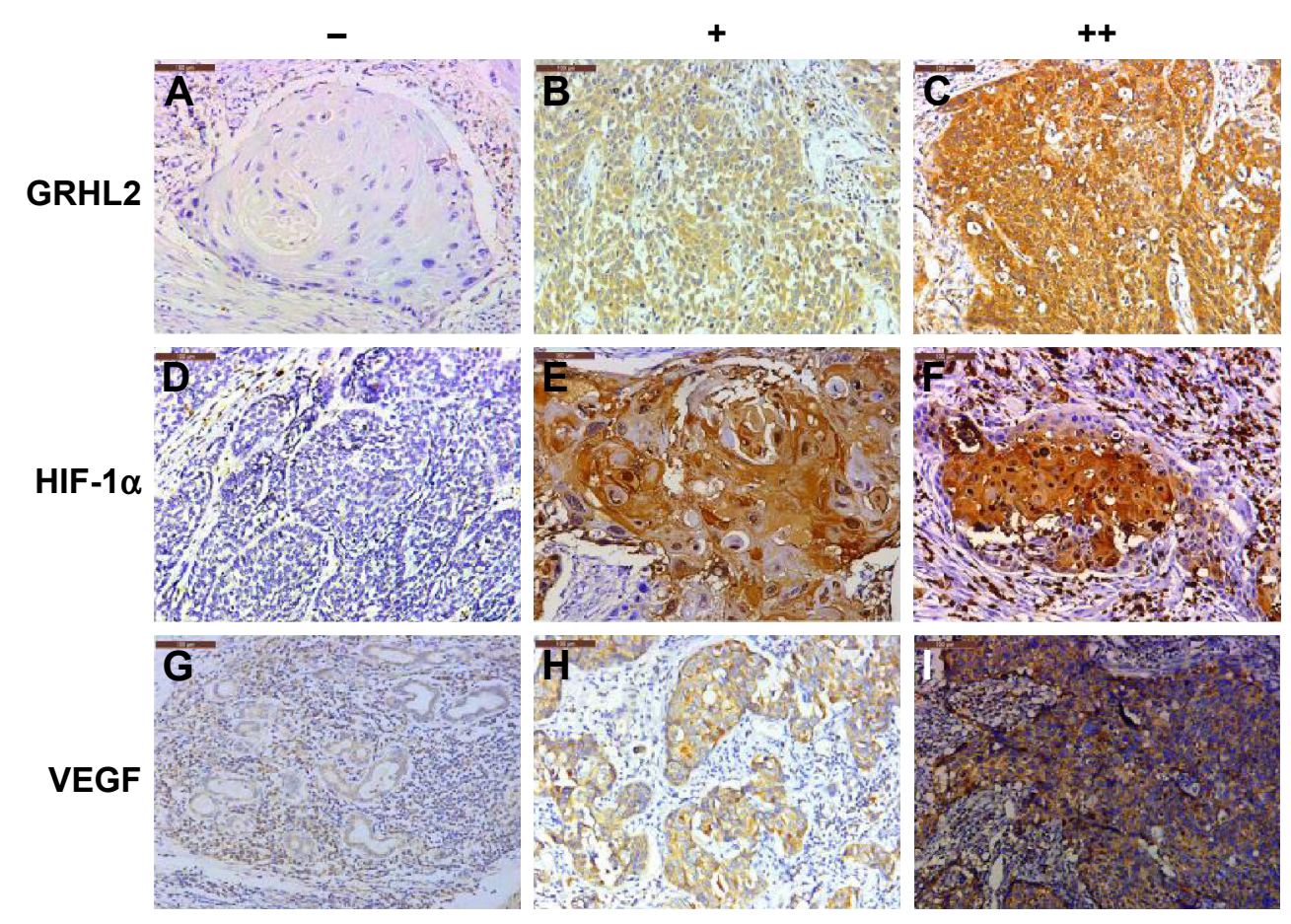

Figure I Expression of GRHL2, HIF-I $\alpha$, and VEGF in esophageal cancer tissues. (A, D, and G) Negative expression of GRHL2, HIF-I $\alpha$, and VEGF. (B, E, and H) Weak positive expression of the three proteins. (C, F, and I) Positive expression of the three proteins. The scale bars are $100 \mu \mathrm{m}$ and the magnification is $\times 200$. Abbreviations: GRHL2, grainyhead-like 2; HIF-I $\alpha$, hypoxia-inducible factor I $\alpha$; VEGF, vascular endothelial growth factor. 
Table I Expression of GRHL2, HIF-I $\alpha$, and VEGF in EC tissue and the corresponding adjacent normal tissues

\begin{tabular}{|c|c|c|c|c|c|c|c|c|c|}
\hline \multirow[t]{2}{*}{ Variables } & \multicolumn{2}{|c|}{ GRHL2 } & \multirow[t]{2}{*}{$P$-value } & \multicolumn{2}{|c|}{ HIF-I $\alpha$} & \multirow[t]{2}{*}{$P$-value } & \multicolumn{2}{|c|}{ VEGF } & \multirow[t]{2}{*}{$P$-value } \\
\hline & Low & High & & Low & High & & Low & High & \\
\hline EC tissue & 47 & 16 & $<0.01$ & 28 & 35 & $<0.01$ & 53 & 10 & $<0.01$ \\
\hline Adjacent normal tissues & 61 & 2 & & 3 & 60 & & 63 & 0 & \\
\hline
\end{tabular}

Abbreviations: GRHL2, grainyhead-like 2; HIF-I $\alpha$, hypoxia-inducible factor I $\alpha$; VEGF, vascular endothelial growth factor; EC, esophageal cancer.

was correlated with tumor differentiation, the relationship among these three proteins was detected. According to the Kaplan-Meier survival analysis, there was no significant relationship between any of the single proteins and survival time including disease-free survival (DFS) and overall survival (OS). The expression of GRHL2 was negatively correlated with HIF-1 $\alpha$; however, no significant relationship was found between GRHL2 and VEGF (Table 3). Furthermore, the association between the expression of GRHL2 and HIF-1 $\alpha$ in EC tissue and the survival time of selected patients was analyzed with Kaplan-Meier survival analysis. The median DFS and OS (Figure 3) in low GRHL2 and high HIF-1 $\alpha$ expression group were significantly shorter than that of other patients (including patients with low GRHL2 and low HIF-1 $\alpha$, high GRHL2 and high HIF-1 $\alpha$, and high GRHL2 and low HIF-1 $\alpha$ expression). However, no significant relationship was found between the expression of GRHL2 and VEGF in EC patients after curative resection (data not shown). These results collectively indicate a functional role of GRHL2 accompanied by HIF- $1 \alpha$ in the progression of EC.

\section{Discussion}

EC is a complex and heterogeneous disease, commonly associated with multiple underlying pathogenic mechanisms caused by various risk factors. Therefore, it is of great significance to identify novel and effective molecular markers for the diagnosis of EC and for the assessment of its treatment. Currently, multiple biomarkers with a potential prognostic value have been investigated for EC, such as VEGF, ${ }^{19}$ cyclooxygenase-2, ${ }^{20}$ E-cadherin, ${ }^{21} \mathrm{CD} 133,{ }^{22}$ and HIF- $1 \alpha ;{ }^{23}$ however, there still remains controversy. Besides, coexpression of multiple biomarkers has also been reported to be a potent poor survival

Table 2 Correlation between the clinicopathological features and the expression of GRHL2, HIF-I $\alpha$, and VEGF in EC

\begin{tabular}{|c|c|c|c|c|c|c|c|c|c|}
\hline \multirow[t]{2}{*}{ Variables } & \multicolumn{2}{|c|}{ GRHL2 staining } & \multirow[t]{2}{*}{$P$-value } & \multicolumn{2}{|c|}{ HIF-I $\alpha$ staining } & \multirow[t]{2}{*}{$P$-value } & \multicolumn{2}{|c|}{ VEGF staining } & \multirow[t]{2}{*}{$P$-value } \\
\hline & Low & High & & Low & High & & Low & High & \\
\hline \multicolumn{3}{|l|}{ Age (years) } & 0.299 & & & 0.292 & & & 0.508 \\
\hline$\leq 50$ & 4 & 0 & & I & 3 & & 3 & I & \\
\hline$>50$ & 43 & 16 & & 27 & 32 & & 50 & 9 & \\
\hline \multicolumn{3}{|l|}{ Gender } & 0.526 & & & 0.176 & & & 0.430 \\
\hline Male & 25 & 8 & & 12 & 21 & & 27 & 6 & \\
\hline Female & 22 & 8 & & 16 & 14 & & 26 & 4 & \\
\hline \multicolumn{3}{|c|}{ Tumor size $(\mathrm{cm})$} & 0.430 & & & 0.444 & & & 0.337 \\
\hline$\leq 5$ & 38 & 12 & & 21 & 29 & & 43 & 7 & \\
\hline$>5$ & 9 & 4 & & 7 & 6 & & 10 & 3 & \\
\hline \multicolumn{3}{|c|}{ Invasion depth } & $<0.001$ & & & 0.588 & & & 0.387 \\
\hline TI & 3 & 4 & & 1 & 3 & & 4 & 0 & \\
\hline $\mathrm{T} 2$ & 16 & II & & 8 & 12 & & 18 & 2 & \\
\hline $\mathrm{T} 3$ & 28 & 1 & & 19 & 20 & & 31 & 8 & \\
\hline \multicolumn{3}{|l|}{ TNM stage } & 0.622 & & & 0.365 & & & 0.025 \\
\hline I & 10 & 5 & & 13 & 7 & & 17 & 0 & \\
\hline II & 20 & 7 & & 11 & 16 & & 22 & 5 & \\
\hline III & 17 & 4 & & 4 & 12 & & 14 & 5 & \\
\hline \multicolumn{3}{|l|}{ Lymph node } & 0.003 & & & 0.498 & & & 0.430 \\
\hline Negative & 17 & 13 & & 12 & 18 & & 26 & 4 & \\
\hline Positive & 30 & 3 & & 16 & 17 & & 27 & 6 & \\
\hline \multicolumn{3}{|c|}{ Tumor differentiation } & 0.047 & & & 0.005 & & & $<0.001$ \\
\hline Well & 7 & 7 & & 12 & 2 & & 14 & 0 & \\
\hline Moderate & 25 & 7 & & 14 & 18 & & 31 & I & \\
\hline Poor & 15 & 2 & & 2 & 15 & & 8 & 9 & \\
\hline
\end{tabular}

Abbreviations: GRHL2, grainyhead-like 2; HIF-I $\alpha$, hypoxia-inducible factor I $\alpha$; VEGF, vascular endothelial growth factor; EC, esophageal cancer. 
A

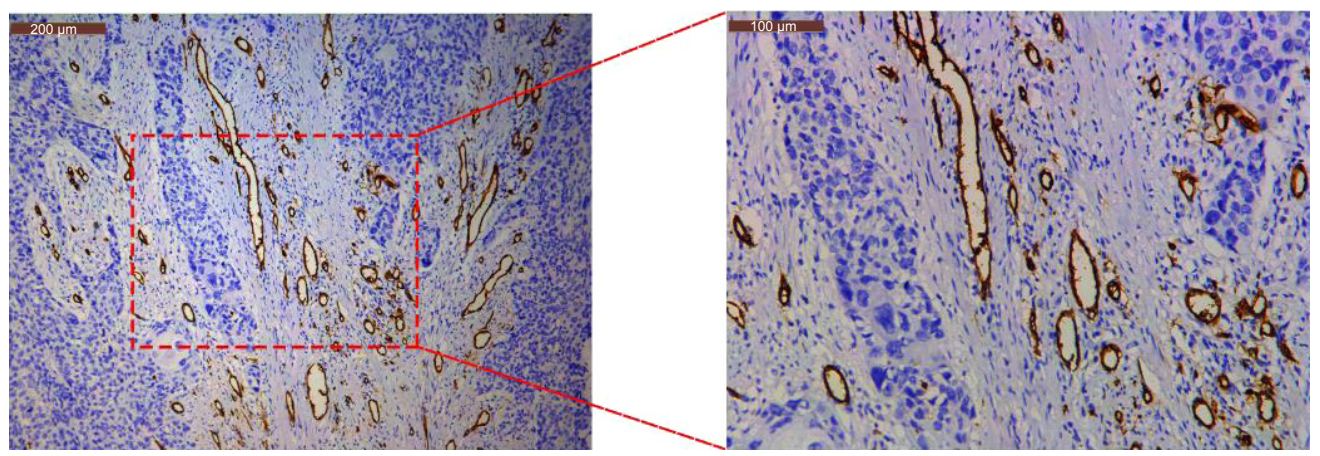

B

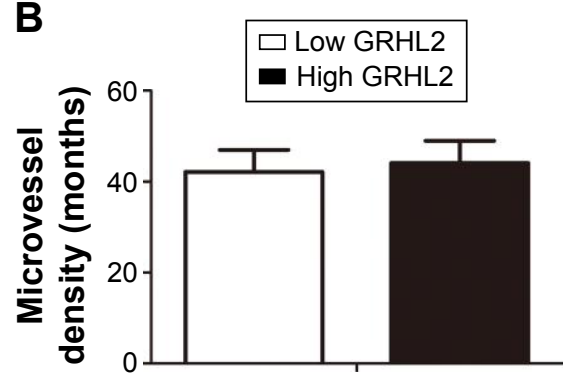

C

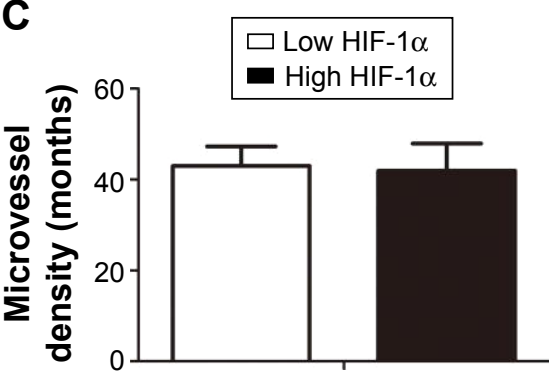

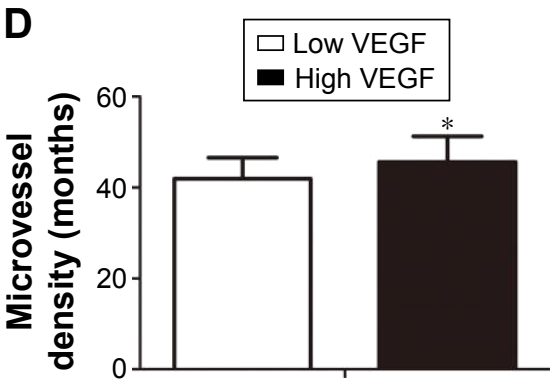

Figure 2 Correlation between GRHL2, HIF-I $\alpha$, and VEGF and MVD. (A) Expression of CD34 analyzed by immunohistochemical analysis. (B) Relative level of MVD in low and high GRHL2 expression groups. (C) Relative level of MVD in low and high HIF- I $\alpha$ expression groups. (D) Relative level of MVD in low and high VEGF expression groups. $* P<0.05$, compared with adjacent tissues. (A) Magnification left image: $\times 100$; right image: $\times 200$.

Abbreviations: GRHL2, grainyhead-like 2; HIF-I $\alpha$, hypoxia-inducible factor I $\alpha$; VEGF, vascular endothelial growth factor; MVD, microvessel density.

predictor for EC. ${ }^{24}$ Recently, a large number of cancer-related proteins have been identified. In the present study, GRHL2 was selected as a candidate protein because it has been reported to be involved in several malignant neoplasms. However, little is known about its expression and role in EC.

GRHL2 is a transcription factor that regulates the EMTrelated processes of wound healing, epidermal junction assembly, and neural tube closure. ${ }^{25-28}$ Although the molecular mechanisms promoting the tumorigenicity of cancer cells undergoing an EMT have remained widely elusive, much interest has been focused on them. Functional implications of EMT include enhanced mobility, invasion, and resistance to apoptotic stimuli. ${ }^{29,30}$ Both HIF-1 $\alpha$ and VEGF are molecules involved in tumor metastasis. HIF- $1 \alpha$ acts as a key mediator of cell metabolism, inflammation, and tumorigenesis under hypoxic conditions. Evidence indicates that during

Table 3 Correlation between GRHL2, HIF-I $\alpha$, and VEGF in EC

\begin{tabular}{|c|c|c|c|c|c|c|}
\hline \multirow[t]{2}{*}{ Variables } & \multicolumn{2}{|c|}{$\begin{array}{l}\text { HIF-I } \alpha \\
\text { staining }\end{array}$} & \multirow[t]{2}{*}{$P$-value } & \multicolumn{2}{|c|}{$\begin{array}{l}\text { VEGF } \\
\text { staining }\end{array}$} & \multirow[t]{2}{*}{$P$-value } \\
\hline & Low & High & & Low & High & \\
\hline \multicolumn{2}{|c|}{ GRHL2 staining } & & 0.04 & & & 0.106 \\
\hline Low & 17 & 30 & & 42 & 5 & \\
\hline High & 11 & 5 & & 11 & 5 & \\
\hline
\end{tabular}

Abbreviations: GRHL2, grainyhead-like 2; HIF-I $\alpha$, hypoxia-inducible factor $\mathrm{I} \alpha$; VEGF, vascular endothelial growth factor; EC, esophageal cancer.
EMT, HIF-1 $\alpha$ induces dissociation of $\beta$-catenin from the E-cadherin/ $\beta$-catenin cell membrane complexes and its translocation into the nucleus where it acts as a promoter of transcription of genes that induce EMT. ${ }^{31}$ Among the targets of HIF- $1 \alpha$, VEGF is correlated with sprouting angiogenesis, lymphangiogenesis, as well as with the dynamic tumorstromal interactions required for the subsequent stages of metastasis. ${ }^{32}$

The present study investigated the expression of GRHL2, HIF-1 $\alpha$, and VEGF in human EC samples using immunohistochemistry. It was found that expression of GRHL2, HIF-1 $\alpha$, and VEGF was higher in EC tissues than the adjacent normal tissues and was associated with tumor differentiation. GRHL2 expression was significantly correlated with lymph node metastasis and invasion depth, whereas VEGF expression was associated with tumor (TNM) stage. Moreover, concomitant expression of GRHL2 and HIF-1 $\alpha$ was found to be associated with the DFS and OS of all patients after curative resection. However, no significant relationship was found between GRHL2 and VEGF.

The present study retrospectively investigated the expression of GRHL1, HIF-1 $\alpha$, and VEGF. Although the main limitation is the number of tested patients, the study reveals that GRHL2, a transcription factor which was thought to function as a tumor suppressor, participates in the development and 

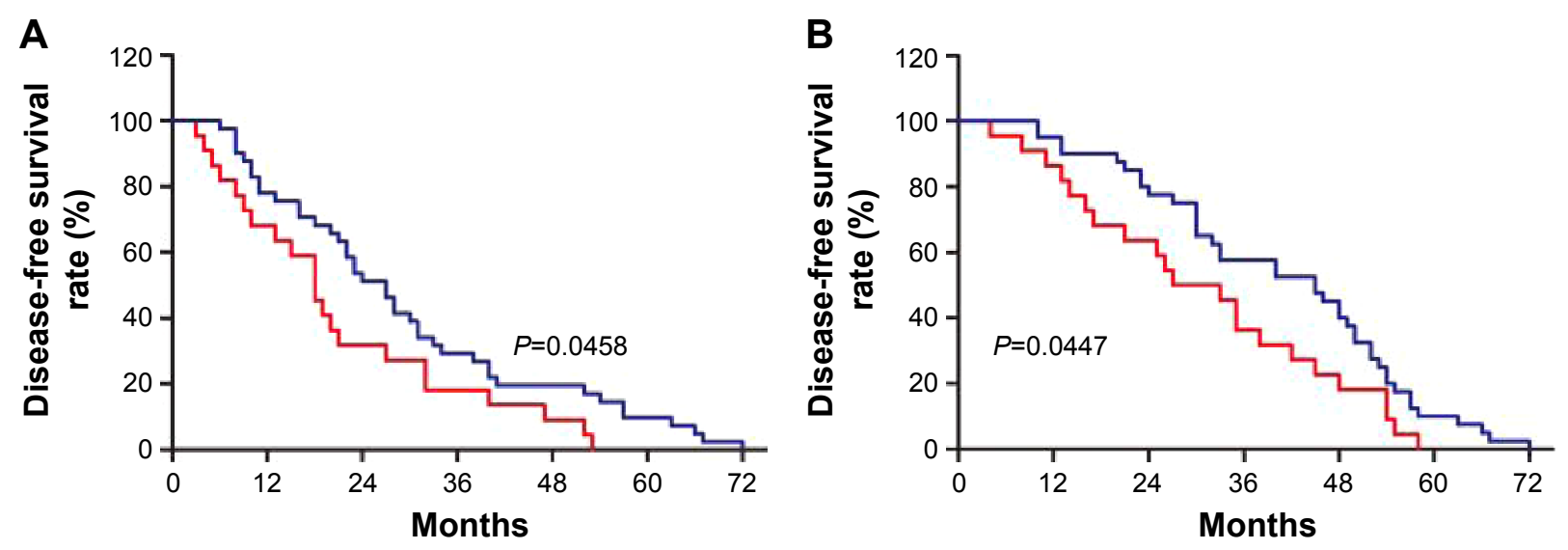

$\perp$ Low GRHL2 + high HIF-1 1 + Others

Figure 3 Kaplan-Meier survival analysis of GRHL2 and HIF-I $\alpha$ expression in esophageal cancer tissues. Low GRHL2 and high HIF-I $\alpha$ expression was correlated with (A) inferior recurrence-free survival and (B) overall survival in esophageal cancer patients.

Abbreviations: GRHL2, grainyhead-like 2; HIF- $\mid \alpha$, hypoxia-inducible factor I $\alpha$.

progression of gastric cancer. Further work focusing on the association of GRHL2 with other cancer-related proteins in more number of patients with $\mathrm{EC}$, and elucidating the role and precise mechanism of GRHL2 in the progression of EC both in vitro and in vivo, is needed.

\section{Acknowledgment}

This work was partly supported by the National Natural Science Foundation of China (no 81472329).

\section{Disclosure}

The authors report no conflicts of interests in this work.

\section{References}

1. Torre LA, Bray F, Siegel RL, Ferlay J, Lortet-Tieulent J, Jemal A. Global cancer statistics, 2012. CA Cancer J Clin. 2015;65(2):87-108.

2. Siegel R, Ma J, Zou Z, Jemal A. Cancer statistics, 2014. CA Cancer J Clin. 2014;64(1):9-29.

3. Siegel RL, Miller KD, Jemal A. Cancer statistics, 2015. CA Cancer J Clin. 2015;65(1):5-29.

4. Edge SB, Compton CC. The American Joint Committee on Cancer: the 7th edition of the AJCC cancer staging manual and the future of TNM. Ann Surg Oncol. 2010;17(6):1471-1474.

5. Mlacki M, Kikulska A, Krzywinska E, Pawlak M, Wilanowski T. Recent discoveries concerning the involvement of transcription factors from the Grainyhead-like family in cancer. Exp Biol Med. 2015;240(11): 1396-1401.

6. Wilanowski T, Caddy J, Ting SB, et al. Perturbed desmosomal cadherin expression in grainy head-like 1-null mice. EMBO J. 2008;27(6): 886-897.

7. Darido C, Georgy SR, Wilanowski T, et al. Targeting of the tumor suppressor GRHL3 by a miR-21-dependent proto-oncogenic network results in PTEN loss and tumorigenesis. Cancer Cell. 2011;20(5):635-648.

8. Cieply B, Riley P 4th, Pifer PM, et al. Suppression of the epithelialmesenchymal transition by Grainyhead-like-2. Cancer Res. 2012;72(9): 2440-2453.

9. Bates RC. Colorectal cancer progression: integrin alphavbeta6 and the epithelial-mesenchymal transition (EMT). Cell Cycle. 2005;4(10): $1350-1352$.
10. Li L, Li W. Epithelial-mesenchymal transition in human cancer: comprehensive reprogramming of metabolism, epigenetics, and differentiation. Pharmacol Ther. 2015;150:33-46.

11. Yang K, Jiang L, Hu Y, et al. Short hairpin RNA-mediated gene knockdown of FOXM1 inhibits the proliferation and metastasis of human colon cancer cells through reversal of epithelial-to-mesenchymal transformation. J Exp Clin Cancer Res. 2015;34:40.

12. Fakhrejahani E, Toi M. Tumor angiogenesis: pericytes and maturation are not to be ignored. J Oncol. 2012;2012:261750.

13. Goel HL, Mercurio AM. VEGF targets the tumour cell. Nat Rev Cancer. 2013;13(12):871-882.

14. Kimbro KS, Simons JW. Hypoxia-inducible factor-1 in human breast and prostate cancer. Endocr Relat Cancer. 2006;13(3):739-749.

15. Zbytek B, Peacock DL, Seagroves TN, Slominski A. Putative role of HIF transcriptional activity in melanocytes and melanoma biology. Dermatoendocrinol. 2013;5(2):239-251.

16. Tanaka Y, Kanai F, Tada M, et al. Gain of GRHL2 is associated with early recurrence of hepatocellular carcinoma. J Hepatol. 2008;49(5):746-757.

17. Xiang J, Fu X, Ran W, et al. Expression and role of grainyhead-like 2 in gastric cancer. Med Oncol. 2013;30(4):714.

18. Xiang X, Deng Z, Zhuang X, et al. Grhl2 determines the epithelial phenotype of breast cancers and promotes tumor progression. PLoS One. 2012;7(12):e50781.

19. Tanaka $T$, Ishiguro $H$, Kuwabara $Y$, et al. Vascular endothelial growth factor C (VEGF-C) in esophageal cancer correlates with lymph node metastasis and poor patient prognosis. J Exp Clin Cancer Res. 2010;29:83.

20. Takatori $H$, Natsugoe $S$, Okumura $H$, et al. Cyclooxygenase-2 expression is related to prognosis in patients with esophageal squamous cell carcinoma. Eur J Surg Oncol. 2008;34(4):397-402.

21. Sasaki K, Natsugoe S, Ishigami S, et al. Significance of Twist expression and its association with E-cadherin in esophageal squamous cell carcinoma. J Exp Clin Cancer Res. 2009;28:158.

22. Okamoto H, Fujishima F, Nakamura Y, et al. Significance of CD133 expression in esophageal squamous cell carcinoma. World J Surg Oncol. 2013;11:51.

23. Tzao C, Lee SC, Tung HJ, et al. Expression of hypoxia-inducible factor (HIF)-1alpha and vascular endothelial growth factor (VEGF)-D as outcome predictors in resected esophageal squamous cell carcinoma. Dis Markers. 2008;25(3):141-148.

24. Kimura S, Kitadai Y, Tanaka S, et al. Expression of hypoxia-inducible factor (HIF)-1alpha is associated with vascular endothelial growth factor expression and tumour angiogenesis in human oesophageal squamous cell carcinoma. Eur J Cancer. 2004;40(12):1904-1912. 
25. Wang S, Samakovlis C. Grainy head and its target genes in epithelial morphogenesis and wound healing. Curr Top Dev Biol. 2012;98: 35-63.

26. Schafer M, Werner S. Cancer as an overhealing wound: an old hypothesis revisited. Nat Rev Mol Cell Biol. 2008;9(8):628-638.

27. Pyrgaki C, Liu A, Niswander L. Grainyhead-like 2 regulates neural tube closure and adhesion molecule expression during neural fold fusion. Dev Biol. 2011;353(1):38-49.

28. Kerosuo L, Bronner-Fraser M. What is bad in cancer is good in the embryo: importance of EMT in neural crest development. Semin Cell Dev Biol. 2012;23(3):320-332.
29. Kalluri R, Weinberg RA. The basics of epithelial-mesenchymal transition. J Clin Invest. 2009;119(6):1420-1428.

30. Scheel C, Weinberg RA. Phenotypic plasticity and epithelialmesenchymal transitions in cancer and normal stem cells? Int J Cancer. 2011;129(10):2310-2314.

31. Zhu Y, Tan J, Xie H, Wang J, Meng X, Wang R. HIF-1alpha regulates EMT via the Snail and beta-catenin pathways in paraquat poisoning-induced early pulmonary fibrosis. J Cell Mol Med. 2016; 20(4):688-697.

32. Carmeliet P, Jain RK. Molecular mechanisms and clinical applications of angiogenesis. Nature. 2011;473(7347):298-307.

\section{Publish your work in this journal}

OncoTargets and Therapy is an international, peer-reviewed, open access journal focusing on the pathological basis of all cancers, potential targets for therapy and treatment protocols employed to improve the management of cancer patients. The journal also focuses on the impact of management programs and new therapeutic agents and protocols on

\section{Dovepress}

patient perspectives such as quality of life, adherence and satisfaction. The manuscript management system is completely online and includes a very quick and fair peer-review system, which is all easy to use. Visit http://www.dovepress.com/testimonials.php to read real quotes from published authors.

\footnotetext{
Submit your manuscript here: http://www.dovepress.com/oncotargets-and-therapy-journal
} 